\title{
Analysis of Application of College Mathematics in HPS Education
}

\author{
Xingjun Li \\ Xijing University, Xi'an Shaanxi, 710123, China
}

Keywords: College mathematics, Course Teaching, HPS education, Application.

\begin{abstract}
HPS education in recent years, the main idea of the International Scientific and Educational Development, has important significance in the development of education in our country. Mathematical talents in all areas of society have a greater demand for the HPS Education in Mathematics Education in Colleges and Universities has become a new form of education. Expand on this article discusses trends in the application of mathematics teaching in Universities HPS education, the use of reasonable application of the policy to explain the significance of the development of the form.
\end{abstract}

\section{Introduction}

HPS education teaching development in pursuit of the main forms of development humanistic, critical and innovative play an important role in today's international education. Moreover, the university is the basic condition of undergraduate mathematics teaching, can reflect the essence of mathematics learning of mathematics as well as the spirit of innovation and scientific spirit, thereby forming an important force for China's development of science and technology.

\section{Application trend of college mathematics in HPS education}

\section{Development trend of times.}

HPS education is the form of globalization under formation, because the main goal is the development of globalization of social science and technology, social science and technology forms. In Mathematics Teaching in Universities, HPS education has become a major form of personnel training, training of scientific and technical knowledge and professional competence is the primary purpose of the whole teaching and training, the need to adapt to the society to cultivate talents. Moreover, the main function of technological development is not infinite, and to promote science and technology, we must promote innovation awareness and make an important contribution to social development. Therefore, mathematics teaching in colleges and universities, the development of HPS education major students expertise and scientific creativity, sense of social responsibility, these organic combination of quality education and training for the community more development talent. HPS education is a key concept of the development of the times, to create favorable conditions for the teaching of mathematics, not only to promote the development and practice of mathematics teaching values need, but also to enable students to master more mathematical knowledge, promote learning of mathematical knowledge to achieve in society the nature and value of the development requirements, and thus play an important social development value for the training of mathematical talent.

\section{Trend of humanistic education combination.}

The main application HPS Education in Mathematics Teaching in Universities is effective in combination with humanistic spirit, with the continuous development of science and technology, people will be science and technology as the primary means of development, science and technology can not only bring greater development of the situation, but also the formation of a hazard. Because people in science and technology development, we should establish a correct consciousness during the development of science and education, first of all, the scientific spirit and humanistic spirit should be effective combination of factors and in accordance with changes in people's psychological changes, changes in thinking and feeling and so comprehensive development [1]. HPS education is the main form of development of science and technology of the times, which includes the history of science, philosophy of science and three science educations, science education is the philosophy of science, 
sociology major form of guidance, can provide more information resources for the history of science. Therefore, the use of HPS education for mathematics teaching colleges and universities, can be analyzed for the mathematical knowledge of the social factors, cultural factors, and the arts and sciences combined unified knowledge, not only enable students to improve values and scientific concept of development of mathematical knowledge, but also mathematical Sciences promote forms of service in the community and promote education for college mathematics favorable.

\section{Students' professional needs.}

As science and technology and social factors, political factors, cultural factors favorable combination of quality modern scientific culture as the basic development tasks. Education Science Education HPS formed and only cultivate talents of society, but to improve people's quality of science, so that people can change things around to watch the attitude, promote good spirit of scientific inquiry, it is possible to form a reasonable choice in life and judgment, and the formation of positive behavior and social development. Therefore, the HPS Education in Mathematics Teaching in Universities, can not only improve students' mathematical science literacy, train more and better mathematical talent, but also to ensure the sustainable development of mathematics. Moreover, since the structure of college students knowledge, ideas formed are relatively rich, abstract way of thinking and philosophy embodied to achieve a higher level of development, the main application for HPS education and knowledge content can be formed more easily accepted Therefore, the HPS Education in teaching, it is possible to achieve greater educational effect, can enhance students' own level.

\section{Application strategy of college mathematics in HPS eduction}

\section{Preferred selection of teaching materials.}

HPS education includes the history of science, philosophy of science, sociology of the three, not only to set forth the nature of science, but also improve the quality of science teaching. Science education is a teaching resource, it can promote the combination of natural science and the humanities, not only can help students form natural science integrity, but also to play a comprehensive knowledge structure. According to the main characteristic of HPS education, the choice of teaching materials during the first, according to the actual needs of real life, the value of selection mathematics teaching knowledge to enable students to form a correct mathematical concepts. Because the development of mathematics is the value of mathematical knowledge in real life exist, enabling students to form a correct idea of cultural and scientific concepts, as a symbolic expression of mathematical knowledge is not abstract, but the basic cultural activities of people's lives, not only to deepen students' understanding of the characteristics of mathematics, but also attach importance to the development of mathematical knowledge needed in society. For example: the development of Neptune, is the application of mathematical knowledge in astronomy. Second, the choice of historical data, show the scientific knowledge in mathematics problem solving and development, so that the students form a correct mathematical thinking. Because knowledge in mathematics is essentially a specimen of, and does not reflect the natural way of thinking, so in mathematics classrooms, teachers should make use of mathematical knowledge of history, to create a classroom inquiry learning atmosphere to stimulate student interest, to enable students to form a larger initiative. Third, during the selection of teaching materials, enabling students to form a unique charisma to enhance students' thoughts and feelings, as a scientific expression of mathematics, for students, with great spirit of inspiration, not only to enhance students self-confidence, but also to enable students to appreciate the rich connotation of mathematical knowledge.

\section{Improve the integration of life.}

In HPS education, the classroom knowledge with a comprehensive knowledge of life, stimulate student interest. According to the main factors associated with the real-life knowledge of mathematics courses on the binding, it can reflect the social value of mathematical science formation. For example: According to Newton's law of transformation of social life, the invention of calculus, which it calculated the orbital velocity curves and movement. In mathematics teaching in colleges and universities, and comprehensive people's social life, mainly based on three-point method. First, based on real life, refine the mathematical knowledge. Because math is formed in real life, it can 
study the spatial variation of the objective world and the number of relationship, and, in real life, can also be found in accordance with the mathematical form of things change. So, in the teaching of mathematics, not only enable students to acquire knowledge, to deepen teachers' understanding of knowledge, but also to promote the rational changes of mathematical knowledge. Second, according to real-life phenomenon, optimize change mathematical thinking. Because the mathematical knowledge and people's lives have a larger relationship, based on knowledge of mathematics teaching in the classroom, using mathematical phenomenon of life related to knowledge transfer. Third, students are able to guide the effective use of knowledge in accordance with relevant, since there is a big limitation of Mathematics Teaching, so that teachers in the classroom teaching, should create favorable conditions and actively guide students to use mathematical knowledge to live practice [2] .

\section{Establish HPS education subject.}

Create HPS education topics, mainly set up specialized courses and teaching seminars. Although in many colleges and universities have set up science and technology-related ideas, philosophy and social studies curriculum theory, but on the content and not systematic, nor to establish a clear teaching objectives and teaching requirements. And the HPS Education in Mathematics Teaching in Universities to form a new teaching philosophy, and promotes the integrity of the HPS education courses. At present, China has studied many HPS education courses and domestic and abroad has formed a new HPS HPS education curriculum based on educational philosophy, not only widely disseminated and promoted in the field of education, but also to give recognition and praise of people. For example: Some science education experts in accordance with the implementation of HPS education curriculum, created the related magazines, academic organizations, not only to provide favorable conditions for the implementation of HPS education curriculum, but also to promote the teaching, the formation of HPS teaching atmosphere. Therefore, the use of HPS education in colleges and universities set up mathematics teaching, not only to create multi-style educational seminars, but also to take advantage of specialized knowledge of scientific knowledge, philosophy, and social knowledge to develop students' horizons, improve the individual's ability to learn. Therefore, in the design of HPS education teaching content, according to student interest, ability to accept students to deepen knowledge of content knowledge to master the ability to promote students' knowledge and understanding.

\section{Application value of mathematics in HPS education}

\section{Promote mathematics professional knowledge.}

HPS Education in Mathematics Teaching in Universities to promote mathematical knowledge and professional skills of students' learning. HPS main forms of development of education will be to reproduce the process of science teaching, especially in mathematics grasp the concept of knowledge as well as the laws and other relevant principles, and these factors have a regular show. In traditional mathematics teaching in colleges and universities to form a mathematical science education are passed directly to the mathematical knowledge, where the richness of expression, authenticity and accidental characteristics of mathematical knowledge are not fully reflected in [3]. Dissemination of mathematical knowledge in the form of the analysis, although this form of education to enable students to have more mathematical content in a short time, but the presence of some unfavorable factors which also affected the positive development of students, such as: the student does not make to complete the task of teaching mathematics in a good environment. If this form of teaching, the HPS Education in Mathematics Teaching in Universities process, not only can help students master the scientific knowledge and relevant expertise, but also to deepen the study of the subject.

\section{Promote formation of rational criticism.}

HPS Education in Mathematics Teaching in Universities to form a rational critical spirit. HPS Education in the development process, the theory of scientific knowledge and scientific knowledge have formed a greater relevance, and the promotion of social construction of subjectivity characteristic is not linear, and scientific development of the revolutionary process of qualitative change. Because of doubts, suspicion, and refute testing and other areas is the focus of scientific development, therefore, the HPS Education in Mathematics Teaching in Universities, not only 
enables students to form a rational critical spirit, promote students to create a dynamic vision of development of science practice, but also reduce some authorities, bound the truth, and the spirit of rational criticism as the development of science education activities and basic requirements.

\section{Improve students' innovative awareness.}

The HPS Education in Mathematics teaching colleges and universities, but also to stimulate their sense of innovation [4]. In the traditional exam-oriented education development, the main mode of teaching students training as the main recipients of teaching knowledge, not to promote students' discovery of new knowledge and enabling innovation in the development of the traditional exam-oriented education, the education level of minute examination into the present Today, the biggest drawback of Education. When the HPS Education in Mathematics teaching colleges and universities, a combination of the effective combination of "Philosophy" and "History", not only to stimulate the teaching of the student's sense of innovation, promote students' creative thinking in modern scientific practice a lot of information utilization under the "Philosophy" and "History" effective combination, but also promoted the scientific creation and development.

\section{Cultivate social responsibility awareness.}

HPS Education in Mathematics Teaching in Universities to foster students' sense of social responsibility [5]. HPS education is not directly to the latest scientific knowledge and scientific results to teach students, but will be a scientific attitude, scientific quality as an important content of education, so that students according to social life experience to reflect on scientific issues. For example: socio-demographic, environmental, energy and ecological problems in the future will be global issues in the development of research as a major problem, not only to make students understand the reality of science and technology and social development of coexistence mode, and understand the social environment for the development of science and technology the real function of the next play, but also rational use of scientific knowledge to solve problems and improve the social development of the state. The HPS Education in Mathematics Teaching in Universities, mainly in the use of social factors on mathematics effectively positioned to enable students to deepen their knowledge of science and mathematics Mathematical Sciences spirit of understanding containing, fully reflects the scientific knowledge of mathematics humanistic value, but also to enable students to form an important sense of social responsibility as well as excellent knowledge of history and culture, and the effective use of this knowledge to the scientific achievements in mathematics, which can ensure the rational development of the human spirit and excellent career.

\section{Conclusions}

Mathematics education in universities is a form of quality education, the students not only to master mathematical concepts, a clear knowledge of mathematical methods and conclusions, but also to understand the nature of mathematical knowledge and social value. The HPS can be formed in many ways educational function of education, not only to promote the theory and practical significance in the form of Mathematical Education, but also to provide advice and recommendations for the Mathematics Education in Colleges and Universities.

\section{References}

[1] Wang Xiaomin. Study on application of HPS education in college mathematics teaching, Teaching research,2013,36(4):41-44..

[2] Xu Jing. Inspiration of International HPS Education and Science for China's Teaching of Science Education Reform, University of Science and Technology Of Hunan (Social sciences),2011,14(6):175-179.

[3] Zhang Jing. Historical Survey HPS Education: science studies into the history of science education, Science and technology management research,2011,31(20):179-182. 
[4] Yuan Weixin. HPS education and college education reform, Modern university education, 2010(1):87-92.

[5] Sun Qingkuo, Hu Qizhou. China's science curriculum and teching reform from HPS view, Jiangxi college of education,2013,34(3):16-19. 